\title{
Progression in healthy ageing: frailty, cognitive decline and gender in the European Innovation Partnership for Active and Healthy Ageing
}

\author{
Lidón Carreteroa \\ Esperanza Navarro-Pardob \\ Antonio Cano ${ }^{\mathrm{a}, \mathrm{c}, *}$ \\ a Instituto Clínico de Valencia (INCLIVA) \\ ${ }^{b}$ Department of Developmental and \\ Educational Psychology, University \\ of Valencia \\ ${ }^{c}$ Department of Pediatrics, Obstetrics \\ and Ginecology, University of Valencia
}

SPAIN

\begin{abstract}
Background and Objectives: Lifespan is getting longer at a global level. More people, therefore, live past 65 years of age. Ageing favors frailty, a condition that makes the body more susceptible to diseases. We present updated information of the European Innovation Partnership on Active and Healthy Ageing (EIP on AHA), and particularly, the Cognitive Decline (CD) group in Action Group 3 (A3), focused in the prevention of frailty and functional decline. Moreover, details of one of the commitments in CD, which deals with the specificities of women in frailty and ageing (Chronic Ailment Reduction after Menopause, CARMEN), will be presented as well. Objectives of EIPAHA are to increase life expectancy of European citizens in two years by 2020 and to improve their quality of life.

Methods: We revised literature and the web of the European Commission in what refers to EIP on AHA, A3 action group, and CD. Furthermore, we have summarized the main aspects of the CARMEN commitment.

Results: We have sketched the main traits of the selected targets. A series of measures has been taken for favoring prevention of frailty and for health promotion of elderly people; this will help to increase the Europeans average healthy lifespan by two years under conditions of improved quality of life.

Conclusions: A new awareness of the need for prevention of frailty and cognitive decline is extending. Early diagnosis of frailty and functional decline are considered as effective measures against age-related comorbidities.
\end{abstract}

Received: 3 August 2015

Revised: 26 October 2015

Accepted: 29 October 2015 


\section{Introduction}

According to 2013 data from the World Health Organization (WHO) life expectancy is 80 years for women and 73 for men in the European Union (UE) ${ }^{1}$. This phenomenon has led at present to a total of 85 million European people over 65 years. It is thought that by 2060 this number will be doubled, accounting for a total of 151 million people ${ }^{2}$. This huge progress in longevity would be blurred if it is not accompanied by improved standards of health and quality of life (QoL). Ageing involves physiological decline, which compromises the response to abrupt changes in health conditions. Consequently old people are more susceptible to suffer diseases, with cancer, diabetes, cognitive decline (CD) or Parkinson being particularly prevalent. In that way the new challenge of overcoming those situations and of improving patient's QoL has emerged.

Frailty can be defined as the inability of an individual to return to their baseline homeostasis after an insult to the body, or a measure of resilience which increases individual's vulnerability for developing increased dependency and/or mortality when exposed to a stressor ${ }^{3}$. Frailty seems to be strongly associated with some chronic diseases, including cardiovascular and pulmonary diseases and diabetes ${ }^{4}$. It has been recognized that frailty may have a biologic basis, with a physical, social and psychological component ${ }^{5}$, but a standardized definition has not yet been established. Not only physical and cognitive status but also depression, anxiety and loneliness may be a sign of frailty. Depending on the definition selected, the estimates of frailty oscillate from $4 \%$ to $17 \%$. There is scientific consensus in that both the high prevalence and the impact on health recommend screening for frailty at population level ${ }^{7}$. Of interest, the impact of ageing is malleable, and ac- cordingly, also is frailty, which is seen as a continuum, where a pre-frail state has been identified. Lifestyle and other interventions may help to slow the ageing toll.

There is no consensus about how to screen for frailty, or about its measurement. The popular biological index requires that three or more of the following criteria are present: weight loss, exhaustion, low activity, slowness and weakness ${ }^{4}$. It is thought that early intervention can be effective in stopping or delaying progression of the process and, consequently, in improving QoL.

Indeed, the attention towards frailty has been the driver for initiatives aiming at the modification of health-care systems. A change from an organization around single-system illnesses towards a more holistic viewpoint of the patient, involving integrated health and social interventions, would result.

\section{European Innovation Partnership on Active and Healthy Ageing (EIP on AHA)}

The European Commission (EC) has issued the European Union Strategy, which pursues the facilitation of the conversion of innovative ideas into products and services. One key action has consisted of the European partnerships. The European Innovation public-private Partnerships (PPPs) combine the resources of governments with those of other agents like academia, research, industry, patient organizations and social health providers in order to deliver societal goals.

As previously commented at a global level, also the European population is ageing rapidly, but living longer does not necessarily mean living healthier, more active and independent. The awareness of this challenge 
has moved to the creation of specific partnerships. One first pilot of these PPP was the European Innovation Partnership on Active and Healthy Ageing (EIP on AHA) on $2012^{8}$. Since then, almost 600 commitments have been submitted by an array of stakeholders involving more than 3,000 partners. This partnership aims at identifying and removing persisting barriers to innovation for active and healthy ageing, through interdisciplinary and cross-sector approaches.

The EC aims at achieving a triple win through EIP on AHA: (i) enabling EU citizens to reach healthy, active and independent lives while ageing; (ii) improving the sustainability and efficiency of social and health care systems; and (iii) boosting and improving the competitiveness of the markets for innovative products and services, responding to the ageing challenge at both EU and global level, thus creating new opportunities for business.

Specific objectives in EIP on AHA are to increase life expectancy of European citizens in two years and improve their QoL by 2020. For that purpose, three priority areas have been established: (i) Prevention, screening and early diagnosis, (ii) Care and cure and (iii) Active ageing and independent living. Five steps were defined in order to reach this objective including building a database of Good Practices, assessment of viability of good practices for scaling up, classification of good practices for replication, facilitating partnerships for scaling up and implementation.

The compilation of Good Practices collects innovative initiatives across EU in the areas of prescription adherence action at regional level, prevention of functional decline and frailty, integrated care, independent living and age-friendly environments ${ }^{9}$. Good Practices integrate into action groups. An Action Group is an assembly of partners committing to work on a number of actions related to ageing. Six different action groups have been defined in EIP on AHA. All of them, summarized in Table 1, have defined their corresponding action plans.

Much of the advancement in the Action Groups has concentrated in promoting exchange for speeding up progression. The particular initiatives have substantiated into the introduction of common tasks, as activities in addition to the particular commitments. Also, a platform for facilitating contact between groups has been introduced (Yammer, https:// www.yammer.com/), and group meetings with responsible Commission officers and annual conferences are organized regularly. There are also specific inter-Groups activities, where topics like synergies, development of a common repository, etc., have been the matter for crossed discussions.

\section{Action plan A3 - Cognitive decline and frailty}

The purpose of the A3 Action Group is the prevention, early diagnosis and management of frailty and of functional decline, both physical and cognitive, in older people. For that reason A3 includes strategies to screen for physical, cognitive, psychological and functional states related to development of frailty ${ }^{10}$. In what regards to prevention, some programs have focused on physical activity and nutrition as lifestyle measures.

Booklets integrating good practices in action groups have been prepared, and so has been the case in A3. The purpose was to have a clearer picture of on-going interventions to prevent frailty. The final text gathers 98 good practices coming from 14 Member States, which includes: Belgium, Cyprus, France, Germany, Greece, Ireland, Italy, Poland, Portugal, Romania, Spain, Sweden, The Nether- 
Table 1

Action Plans concerning EIP on AHA.

Name Description and subgroups

A1 Finding innovative ways to ensure that patients follow their prescriptions and treatments.

Finding innovative solutions to better manage our own health and prevent falls.

A2

- Data and evidence: research

- Implementation: evidence based standards, best practice guidelines and toolkits

- Governance: support, sharing, scaling up and sustainability

Helping to prevent functional decline and frailty.

- Frailty and Functional decline

A3

- Cognitive decline

- Nutrition

- Dependency and caregivers

- Physical activity

Promoting integrated care models for chronic diseases, including the use of remote monitoring.

- Organizational Models

- Change management

B3 - Workforce development

- Risk stratification

- Care pathways

- Patient/user empowerment

Deploying solutions to help older people stay independent and more active for longer.

- Management and coordination

C2 Collating and sharing practice

- Analysis, guidelines and recommendations

- Promotion and dissemination

Promoting innovation for age-friendly and accessible buildings, cities and environments.

- Implementing Policies and Practices for Regions, Cities and Communities

D4 - Networks promoting an EU Covenant on Demographic Change

- The Spatial Context

- ICT and Smart Environments

lands and United Kingdom. Table 2 shows integrated care good practices taking part in Action Group A3 by countries.

The implication of the EC in the promotion of EIP on AHA has included specific funding within the Calls of the research programme. For example, the Consumers, Health, Agricul- ture and Food Executive Agency (CHAFEA) is funding several research projects. One of them is the Frailty management Optimisation though EIP AHA Commitments and Utilisation of $\underline{S}$ takeholders input (FOCUS). The purpose of FOCUS is to critically reduce the burden of frailty in Europe by assisting those partners within the European Innovation Part- 
Table 2

Integrated care good practices by countries.

\begin{tabular}{lccccccc} 
Country & $\begin{array}{c}\text { All Good } \\
\text { Practices }\end{array}$ & $\begin{array}{c}\text { Frailty in } \\
\text { general }\end{array}$ & $\begin{array}{c}\text { Functional } \\
\text { Decline }\end{array}$ & $\begin{array}{c}\text { Cognitive } \\
\text { Decline }\end{array}$ & $\begin{array}{c}\text { Nutrition } \\
\text { Caregivers \& } \\
\text { dependency }\end{array}$ & $\begin{array}{c}\text { Physical } \\
\text { exercise }\end{array}$ \\
\hline Belgium & 2 & 0 & 0 & 0 & 2 & 0 & 0 \\
\hline Cyprus & 2 & 0 & 1 & 1 & 0 & 0 & 0 \\
\hline France & 1 & 0 & 0 & 0 & 1 & 0 & 0 \\
\hline Germany & 2 & 2 & 0 & 0 & 0 & 0 & 0 \\
\hline Greece & 3 & 1 & 0 & 2 & 0 & 1 & 0 \\
\hline Ireland & 17 & 7 & 2 & 2 & 3 & 1 & 2 \\
\hline Italy & 2 & 2 & 0 & 0 & 0 & 0 & 0 \\
\hline Poland & 17 & 1 & 2 & 6 & 2 & 3 & 3 \\
\hline Portugal & 2 & 1 & 0 & 0 & 0 & 1 & 0 \\
\hline Romania & 30 & 8 & 5 & 7 & 3 & 6 & 1 \\
\hline Spain & 1 & 1 & 0 & 0 & 0 & 0 & 0 \\
\hline Spain/Poland/Finland & 3 & 1 & 0 & 0 & 1 & 1 & 0 \\
\hline Sweden & 5 & 2 & 0 & 1 & 0 & 1 & 1 \\
\hline The Netherlands & 9 & 4 & 0 & 1 & 3 & 0 & 1 \\
\hline UK & 98 & 30 & 10 & 21 & 15 & 14 & 8 \\
\hline Total & & & & & & & 0 \\
\hline
\end{tabular}

nership for Active Healthy Ageing (EIPAHA) with commitments focusing on early diagnosis/screening and/or management of frailty to achieve scalability.

The project offers both a service and a network. The service consists of evidence-based guidelines to critically help the selected group of partners to satisfactorily achieve their goals. The network intends to prolong the service in the long term.

To achieve that purpose FOCUS will define the roadmap, in that it will i) describe the state of art (review of the scientific literature), ii) get a picture of the status of the affected commitments within EIP on AHA (barriers, enablers, etc.), and iii) obtain information of the needs of stakeholders. With this realworld landscape in hand, FOCUS will define indicators and use a scientifically sound method, comparative effectiveness research, to draw conclusions regarding the most adequate and customized approach to assist commitments in achieving success. Inequalities, cultural conditions or cross-border issues will be considered as representative of the diversity in Europe. Guidelines and toolkits will be issued with the perspective of sustainability. Moreover, FOCUS will constitute the "Platform for Knowledge Exchange" (PKE), which will both facilitate and perpetuate exchange between partners and stakeholders to achieve synergies and guide progression. PKE will act as a repository and as an instrument for dissemination too. The work package 7 (WP7) will be a practical test to verify the usability and performance of guidelines in real EIPAHA commitments. 


\section{Cognitive decline (CD) in A3}

CD constitutes one subgroup within A3. Integrated by some thirty different partners, CD is developing a series of common tasks, which add to the respective individual commitments of the partners ${ }^{11}$. Important tasks constitute the initiative to update conceptual aspects, as reflected by a series of articles already published $^{12}$ or submitted; the integration of databases, the pilot use of ICT (Information and Communication Technology) based serious games to screen for frailty and CD, etc.

An important interest within cognitive decline has focused in cognitive frailty. The reason is the certainty that, as other organs, brain also suffers from the exhaustion associated with ageing. In support of that, both crossed and longitudinal studies have detected a correlation between physical frailty and cognitive deterioration. This is why a recent consensus has defined cognitive frailty, which results by the concurrence of physical frailty with potentially reversible cognitive impairment ${ }^{13}$. Importantly, individuals with confirmed Alzheimer's or other dementias are excluded from the definition.

\section{The impact of gender}

One important issue concerns the contrast between men and women when considering different dimensions. This has been confirmed, for example, for life expectancy (LE) and healthy-life years (HLY) ${ }^{14}$. Also, the QoL of women is compromised, especially after menopause. Hormonal levels and age make them more susceptible to diseases like osteoporosis or cardiovascular disease. The growing sensitivity to this scenario in both population and health professionals has favored an exaggerated administration of drugs for chronic disease prevention.
The Chronic Ailment Reduction after MENopause (CARMEN) cohort is one commitment within CD that includes 1,200 elderly women, which have been followed since 2008. CARMEN includes clinical and analytical data about community-living women from the urban area of Valencia. Among the initiatives of CARMEN, there is a protocol capable of integrating data about frailty, physical and cognitive status at screening. There is also one intervention measure consisting of the implementation of physical activity to assess the impact on physical and psychological health. Details of this commitment can be obtained on the Good Practices Guide ${ }^{9}$. As a relevant issue, women are being introduced into the use of information and communication technologies (ICT) to increase compliance with physical activity. In order to screen for psychological and cognitive frailty some tests are being applied: Adeenbrooke's Cognitive Examination (ACE), Hospitality Anxiety and Depression Scale (HADS) and an Index of deficits. Questions regarding loneliness, temporal orientation, social relationship or emotional and intellectual activity are also integrated in the protocol.

\section{Conclusion and Future directions}

The EC has developed EIPonAHA with the purpose of implementing new strategies to improve the prevention and early diagnosis of frailty and diseases related to age. The challenge is to ensure that people not only live longer, but also healthier and more active. EIP on AHA is structured into six Action Groups with different perspectives. In the present report we have concentrated on A3, the group focused on frailty and cognitive decline. A3 includes 98 good practices. It is believed that lifestyle, including physical ac- 
tivity and diet, is one good measure for preventing the disorders associated with age. The scalability of good practices, together with expansion of research in effective interventions, should increase the benefits in terms of healthy longevity.

\section{Acknowledgments}

This study was supported by the Instituto Clínico de Valencia (Instituto de Investigación Sanitaria) and by the University of Valencia (UV). The work of AC was supported by the grant PI12/02775 from Instituto de Salud Carlos III, Fondo de Investigación Sanitaria, Ministerio de Sanidad y Consumo, Madrid, Spain, and the European Regional Development Fund (ERDF).

\section{Conflict of Interest}

The authors do not have conflicts of interest.

\section{References}

1. Better palliative care for older people. World Heal Organ Press [Internet]. 2004. [Accesed on 10th July 2015]. Available from: http://www.euro.who.int/_data/assets/pdf _file/0009/98235/E82933.pdf

2. Comission E. Aging report: Economic and budgetary projections for the EU-27 Member States (2008-2060) [Internet]. [Accesed on 10th July 2015]. Available from: http:// ec.europa.eu/economy_finance/publications/publication 14992_en.pdf

3. Clegg A, Young J, Iliffe S, Rikkert M, Rockwood K. Frailty in elderly people. Lancet. 2013; 2; 381 (9868): 752-62.

4. Fried LP, Tangen CM, Walston J, Newman AB, Hirsch C, Gottdiener J, et al. Frailty in Older Adults: Evidence for a Phenotype. Journals Gerontol Ser A Biol Sci Med Sci. 2001; 56(3): M146-57.
5. Uchmanowicz I, Wleklik M, Gobbens RJJ. Frailty syndrome and self-care ability in elderly patients with heart failure. Clin Interv Aging. 2015; 10: 871-7.

6. Collard RM, Boter H, Schoevers RA, Oude Voshaar RC. Prevalence of frailty in community-dwelling older persons: a systematic review. J Am Geriatr Soc. 2012; 60(8): 1487-92.

7. Morley JE, Vellas B, van Kan GA, Anker SD, Bauer JM, Bernabei R, et al. Frailty consensus: a call to action. J Am Med Dir Assoc [Internet]. 2013; 14(6): 392-7.

8. Commission E. EIP on AHA. [Accesed on 15th July 2015]. Available from: http://ec.europa.eu/research/innovation-union/index_en.cfm?section=active-healthy-ageing.

9. Gomez MI, Garcia-Sanchez I, Carta A, Pinto Antunes J. A compilation of good practices [Internet]. European Commission. 2013. [Accesed on 15th July 2015]. Available from: http://ec.europa.eu/research/innovation-union/pdf/activehealthy-ageing/gp_a3.pdf\#view=fit\&pagemode=none

10. Partners I. European Innovation Partnership on Active and Healthy Ageing ACTION PLAN on "Prevention and early diagnosis of frailty and functional decline, both physical and cognitive, in older people.” 2012. [Accesed on 22th July 2015]. Available from: https://ec.europa.eu/research/innovationunion/pdf/active-healthy-ageing/a3_action_plan.pdf [

11. Commission E. Action Group A3 on Prevention of Frailty \& Functional Decline. Main Achievements \& Targets for 2015. 3rd Conference of Partners. [Accesed on 22th July 2015]. Available from: https://ec.europa.eu/research/innovation-union/pdf/active-healthy-ageing/a3_2014.pdf

12. Calzà L, Beltrami D, Gagliardi G, Ghidoni E, Marcello $\mathrm{N}$, Rossini-Favretti R, et al. Should we screen for cognitive decline and dementia? Maturitas. 2015; 82(1): 28-35.

13. Robertson DA, Savva GM, Kenny RA. Frailty and cognitive impairment-a review of the evidence and causal mechanisms. Ageing Res Rev. 2013; 12(4): 840-51.

14. Jagger C, Gillies C, Moscone F, Cambois E, Van Oyen $\mathrm{H}$, Nusselder $\mathrm{W}$, et al. Inequalities in healthy life years in the 25 countries of the European Union in 2005: a cross-national meta-regression analysis. Lancet. 2008; 372(9656): 2124-31.

\footnotetext{
* Corresponding author:

Antonio Cano

Dept. Pediatrics, Obstetrics and Gynecology

Av Blasco Ibáñez, 15

46010 Valencia, Spain

E-mail: Antonio.Cano@uv.es
} 